\section{Обоснование выбора системы лесосечных машин для проходных рубок ухода}

\author{
Ю. В. Суханов ${ }^{1}$ \\ Петрозаводский государственный университет
}

\begin{abstract}
АНОТАЦИЯ
Статья посвящена проблемам выбора систем машин для проходных рубок ухода. Сделана попытка обосновать правильность выбора с точки зрения максимизации прибыли, которую можно получить от рубок ухода, применяя ту или иную технику. Рассмотрены вопросы моделирования проведения вторых и третьих рубок, а также моделирования хода роста древостоев.
\end{abstract}

Ключевые слова: рубки ухода, лесные машины, ГИСтехнологии.

\section{SUMMARY}

The article focuses on the choice of the logging machinery for thinning. We attempted to motivate the criteria of choice considering possible profit growth, which can be achieved through thinning, in the cases when different machines are used. The article covers the issues of modeling second and third thinnings as well as of modeling process of forest growth.

Keywords: thinnings, forest machines, GIS technology.

Увеличить объем лесопользования в России можно двумя путями: вводить в эксплуатацию новые, еще неосвоенные, территории или получать больший выход леса с уже освоенных территорий. И хотя первый путь проще, но, учитывая то, что спелых и преспевающих лесов становится все меньше, путь повышения интенсивности использования уже освоенных территорий является более перспективным. В Скандинавских странах с одного гектара получают почти в три раза больше лесоматериалов, чем в России, это тоже говорит в пользу второго пути.

Одними из мероприятий, повышающих выход деловой древесины, в первую очередь на главной рубке, и дающих возможность получать древесину для промышленных нужд от промежуточного пользования, являются рубки ухода. По оценкам отечественных специалистов, правильно проведенные рубки ухода позволят повысить продуктивность лесов на 30-40\%.

Основной целью рубок ухода является выращивание хозяйственно ценных и высокопродуктивных насаждений за счет отбраковки худших деревьев и деревьев менее ценных пород и равномерности размещения деревьев, что улучшает световые и тепловые режимы, вызывает активизацию фотосинтеза, дыхания и минерального обмена. При этом сокращается срок вы-

\footnotetext{
${ }^{1}$ Автор - аспирант кафедры тяговых машин

(C) Ю. В. Суханов, 2003
}

ращивания высококачественной древесины, повышается устойчивость экосистемы [1].

Однако широкое применение рубок ухода невозможно при низком уровне машинизации. При этом требуется, чтобы машины удовлетворяли требованиям по производительности и возможности выполнения программы рубок. А главное, машины должны быть как можно более средощадящими. Особенно надо обращать внимание на минимизацию повреждений деревьев, оставляемых на доращивание. При неправильно проведенных рубках ухода может наблюдаться и обратное: получение меньшего выхода древесины с лесосеки.

Качество проведения рубок ухода и, в конечном итоге, экономический эффект от них будут в первую очередь зависеть от правильного выбора системы машин для рубок ухода. Однако не менее важна высокая квалификация операторов машин, хорошая организация работ и правильный выбор насаждений для проведения рубки.

При проведении рубок ухода необходимо отдавать предпочтение высокопродуктивным 30- 40-летним древостоям Ia-II класса бонитета с плотностью не менее 0.8 Проведение рубок ухода в древостоях, имеющих меньшую плотность, не повышает общую продуктивность леса, а даже уменьшает ее и проводить рубки ухода там невыгодно [2].

Задача оптимального выбора непростая - на качество проведения рубок ухода будет влиять множество факторов: характеристики древостоя, почвенный покров, рельеф местности, климатические условия и, конечно, характеристики машин.

Различные системы машин для выполнения рубок ухода и соответствующая им технологическая организация работ имеют разную производительность и не одинаково влияют на природную среду.

Для сравнительного анализа работы существующих машин можно применить лесоводственноэкономическую оценку, которую можно получить, построив имитационную модель лесосечного процесca.

Оценка с экономической точки зрения является наиболее точной по следующим причинам:

- $\quad$ во-первых, это получение большего количества древесины хорошего качества и получение древесины от промежуточного пользования, т.е. получение большей прибыли с единицы площади леса и есть конечная задача проведения рубок ухода;

- во-вторых, современная лесозаготовительная техника, особенно харвестеры, довольно дорогая как сама по себе, так и при эксплуатации, и поэтому нельзя оценить, что будет выгоднее: использование харвестера + форвардера или вальщиков + форвардера, опираясь только на крите- 
рии качества, производительности и полноты выполнения программы.

Варьируя типами машин можно получить оптимальную по составу систему или оптимизировать параметры проектируемых машин.

Для определения эффективности рубок ухода надо рассмотреть период от первой рубки ухода и до главной рубки включительно. Экономический эффект от рубок ухода имеет три основных составляющих:

1. Улучшение качества и, следовательно, повышение ценности будущего спелого древостоя.

2. Получение дополнительной древесины в неспелом лесу и увеличение общего размера еe использования с единичной площади.

3. Уменьшение времени оборота рубки.

Есть и другие положительные эффекты (например, повышение устойчивости древостоя против неблагоприятных факторов), но они труднее поддаются оценке.

Также рубки ухода создадут дополнительные рабочие места, что само по себе положительно скажется на социально-экономической сфере республики.

За основной показатель можно взять коэффициент эффективности, определяемый как соотношение добавочной прибыли (эффект) от рубок ухода и дополнительных затрат на проведение мероприятий, с помощью которых достигается эффект, при сопоставлении с вариантом выращивания вообще без рубок ухода. Расчет должен учитывать дополнительную прибыль, полученную на главной рубке (более качественный, однородный и крупный древостой), прибыль промежуточного пользования (реализация лесопродукции от промежуточного пользования), прибыль от уменьшения оборота рубки при использовании рубок ухода, а также расходы: капиталовложения на строительство дорог (отнесенных на счет рубок ухода, частично их можно использовать и на главной рубке) и их содержание, стоимость проведения самих рубок ухода. Для того чтобы исключить влияние инфляции, скачков цен и других неблагоприятных факторов, параллельно можно оценить правильность выбора системы машин с помощью сравнения объемов древесины, полученной с рубками ухода или без них.

Эффективность проведения рубок ухода сильно зависит от реализации древесины от промежуточного пользования. В основном ее можно использовать в целлюлозно-бумажной промышленности, при изготовлении древесностружечных и древесноволокнистых плит, тары и клепки, как дрова или для удобрений. Древесина от рубок ухода имеет большую себестоимость потому, что она низкокачественная и мелкоразмерная, применяется дорогостоящая техника и сложные работы. И хотя надо стремиться к окупаемости проходных рубок за счет древесины от промежуточного пользования, но не во вред рубке главного пользования. Количество деревьев, отведенных в рубку ухода, должно быть на 10-20\% больше, чем количество потенциального отпада.

Если хозяйство может продавать древесину от рубок ухода, то обычно применяют три рубки ухода за время выращивания древостоя, если не может продавать, то две [3].

Однако вторые и третьи рубки ухода невозможно моделировать без учета хода роста древостоя между рубками. Также без моделирования роста древостоя невозможно оценить экономический эффект от рубок ухода.

На ход роста древостоя влияет множество факторов: условия и место произрастания, состав древостоя, густота и сомкнутость полога [4].

Для каждой породы есть свои оптимальные количество света, влажность и глубина залегания грунтовых вод, тепловой режим, оптимальные грунтовые условия.

В различных климатических районах ход роста также будет протекать по-разному.

Моделирование однородных насаждений может основываться на региональных таблицах роста, при создании которых исходными данными служили пробные площади. Обычно в таблицах ход роста зависит от района, типа леса, класса возраста, класса бонитета и полноты.

Наиболее сложно моделируется ход роста в смешанных древостоях, так как в этих насаждениях идет конкуренция не только между деревьями одной породы, но и между породами. Это серьезно влияет на возрастную динамику развития древостоя. Также в модели требуется учитывать воздействие на динамику хода роста насаждений рубок ухода, которые изменяют густоту, полноту, запас, состав, средние диаметры и средние высоты по породам. Серьезно отличается воздействие на древостой у различных типов рубок (верховой, низовой или комбинированный).

Поэтому при моделировании хода роста необходимо использовать математические зависимости, описывающие ход роста, текущий прирост и отпад, которые только частично опираются на региональные таблицы роста, так как в таблицах обычно прогнозируется динамика чистых древостоев, не подверженных влиянию лесохозяйственных мероприятий.

Получив модель хода роста, можно оптимизировать число промежуточных рубок, период их повторяемости и оптимальное количество деревьев, которое необходимо назначить в рубку за каждый прием.

Проведение рубок ухода моделируется следующим образом: генерируется на основании данных о климатическом районе, составе, запасе, возрасте, классе бонитета и др. горизонтальная и вертикальная структуры древостоя. Если моделируются вторые или тре- 
тьи рубки, то исходными данными являются выходные данные моделирования роста древостоя, подвергнувшегося первым рубкам ухода. Также генерируются, в зависимости от района, рельеф (уклоны местности) и грунтовые условия.

Эта информация является исходными данными для имитационной модели технологии работ, где методом перебора рассчитываются критерии работы системы машин (качество проведения работы, точность следования намеченной программе рубок, производительность и т.д.) для рубок ухода. После этого с помощью модели роста хода древостоя рассчитываются параметры древостоя, измененные за период между рубками ухода или между рубкой ухода и главной рубкой.

Рассчитанные критерии, данные, характеризующие состояние древостоя перед главной рубкой, а также остальные данные, требуемые для экономической оценки, являются входными параметрами для лесоводственно-экономической модели, в которой, сравнивая вариант выращивания насаждения с рубками ухода и без них, можно оценить экономический эффект от проведения рубок ухода с помощью той или иной системы машин.

Данные математические модели в совокупности должны позволить лесозаготовителям рационально подобрать систему машин или машину для имеющегося лесного фонда, определить подходящие условия работы для существующей системы машин или машины. А также модель может позволить производителям лесных машин оптимально рассчитать основные проектные параметры и выбрать аналоги для проектирования новой машины с учетом будущих условий эксплуатации.

\section{СПИСОК ЛИТЕРАТУРЫ}

1. Веретенников А. В. Физиологическое обоснование некоторых лесохозяйственных мероприятий // Анатомия, физиология и экология лесных растений. Петрозаводск, 1992.

2. Сеннов С. Н. Варианты программ рубок ухода в сосняках по результатам длительного опыта // Лесоводство, лесные культуры и почвоведение. СПб., 1993.

3. Мартынов А. Н. Целевые программы рубок ухода за лесом. СПб., 1991.

4. Филлиппов Г. В. Моделирование роста смешанных древостоев с хозяйственным воздействием на основе прогнозирования текущего прироста / ЛенНИИЛХ. Л., 1986. 